\title{
A RAE NOS SEUS 45 ANOS
}

\author{
Carlos Osmar Bertero \\ Professor da FGV-EAESP. Diretor e editor da RAE \\ E-mail: cbertero@fgvsp.br
}

A celebração de aniversários sempre desperta sentimentos ambivalentes. Quando são aniversários de pessoas, ela é geralmente festiva. Apenas deixa de sê-lo quando as pessoas acham que já está na hora de deixar de celebrar e passar a ocultar as indesejadas datas. Mas quando se trata de organizações, países, instituições e, naturalmente, publicações científicas, há sempre orgulho em colecionar aniversários. Não poderia ser diferente com a nossa RAE-revista de administração de empresas, que está a completar seu 45 aniversário.

Pessoalmente, experimento grande ambivalência, oscilando entre o orgulho e o embaraço de ter acompanhado a revista ao longo destes 45 anos. Explico-me. Quando a RAE foi lançada, pelo saudoso Raimar Richers, eu era aluno do primeiro "experimento" de pós-graduação que a EAESP realizou, ainda com os professores da missão universitária da Michigan State University. Ocupei o cargo de redator-chefe por um par de anos quando retornei de meu mestrado. Assumi novamente a revista em 2005, quase 40 anos depois. Isso me permite realizar aqui um exercício de avaliação, crítica e saudosismo.

\section{PRIMEIROS ANOS}

Se compararmos o que é a RAE atualmente com o que ela foi, não somente no momento do início de sua circulação, mas em diversas etapas intermediárias, como foram relatadas por alguns de seus editores que me antecederam, encontraremos grandes diferenças.

Na verdade, editar uma revista de Administração de Empresas em 1961 foi uma ousadia. O país mal começara a ter cursos de graduação em Administração. As primeiras turmas da FGV e da USP ainda estavam nos bancos escolares e se lançou uma revista. A ótica então era diversa da que hoje existe. Não se pretendia que a revista fosse um outlet de produção científica. Mesmo porque produção científica como hoje a entendemos não existia. Pretendia-se ter um periódico que divulgasse um novo campo de ensino, cujos cursos de graduação haviam acabado de abrir, e que também ajudasse a firmar a imagem de uma nova escola, que era a EAESP - Escola de Administração de Empresas de São Paulo da Fundação Getulio Vargas.

Portanto, se compararmos a RAE de hoje com a que circulou na dé- cada de 1960, veremos que estamos diante de duas revistas bem diferentes. Nada de ofensivo ou destoante nessa colocação. A diversidade da RAE ilustra o itinerário percorrido pela área de Administração entre nós, tanto em termos de ensino como de pesquisa e publicação da produção científica que veio a ser gerada a partir da década de 1970 .

Durante a primeira década de sua publicação, a RAE enfrentava muitas dificuldades. Havia poucos artigos, e uma enorme dificuldade para se fechar a revista. Simplesmente porque havia muito pouca gente que escrevesse sobre Administração e menos gente ainda escrevendo sobre Administração de Empresas. Como a área estava no seu início, o que se esperava dos professores era que dessem aulas. A ênfase da profissão acadêmica então era para ensino e não para pesquisa e produção científica. Se um professor também escrevesse e pesquisasse, isso era uma atividade complementar e não central em sua vida profissional. Dir-se-ia que o faziam aqueles que se sentiam mais inclinados a isso. Mas não se exigia de profissionais da academia em Administração que apresentassem o que hoje cha- 
mamos de produção científica. Era importante que dessem aulas. A nova área tinha que se fazer presente rapidamente e junto aos públicos considerados importantes para sua consolidação. Daí se entende que o primeiro curso que a EAESP ofereceu, antes mesmo de seu curso de graduação com duração de quatro anos, tenha sido um curso de Educação Executiva. Era em regime de tempo integral, em que executivos de cúpula das empresas eram convidados a realizar uma experiência, até então inédita no país, de imersão total.

A RAE tinha um redator-chefe, equivalente ao editor de hoje, e um Conselho Editorial que o apoiava. Não havia blind review, e a decisão sobre o que publicar ficava com o redator-chefe. Os critérios sobre o que deveria ser publicado precisariam ser resgatados. Primeiramente, não se pretendia que a revista fosse inovadora. Acabava por se publicar material que, mesmo sem conter algo de novo, versava um assunto que ainda não se encontrava em língua portuguesa. Isso porque, sendo a área nova, tudo que se publicasse acabava sendo novidade para a quase totalidade do público leitor. Não existia conseqüentemente uma separação entre artigos científicos e aqueles voltados a um público de profissionais. Embora isso possa parecer estranho e primitivo atualmente, deve ser registrado que a situação não era muito diversa nos Estados Unidos, a meca do management desde aquela época. A clara divisão do mundo das publicações em Administração em periódicos acadêmicos ou científicos e profissionais só começou a se fixar a partir da década de 1970. Muitas universidades norte-americanas tinham publicações que mesclavam os dois universos. Diria que até hoje há vestígios dessa mescla em revistas de prestígio como a Sloan Management
Review, publicada pela Sloan School, do MIT (Massachusets Institute of Technology), e a California Management Review, publicada pelo campus de Berkeley da University of California.

$O$ projeto de criação da RAE era fazer dela, além de uma revista que buscava divulgar e conferir visibilidade à EAESP, um órgão do recémcriado CPP (Centro de Pesquisas e Publicações). Dessa forma, desde o início se afirmava a intenção de que a Escola fosse também um centro gerador de conhecimento sobre a realidade administrativa do Brasil. Foram publicados na primeira década alguns artigos em que se davam a público os resultados das primeiras pesquisas realizadas na Escola.

Outra característica dos primeiros anos era a publicação de um artigo traduzido. Era simultaneamente uma forma de preencher a carência de artigos de autores locais e também de procurar publicar artigos em português que fossem de particular interesse. Uma fonte importante de artigos traduzidos foi a Harvard Business Review, que sempre cedeu generosamente seus direitos autorais para publicação na RAE. Dado o pioneirismo da EAESP, entende-se que os autores fossem quase que exclusivamente professores da instituição. Ainda não havia condições para que a revista se "desprovincianizasse", buscando representar a comunidade de professores e pesquisadores de Administração do país. Era ainda cedo, e a EAESP era o primeiro núcleo, seguido pouco depois pela Universidade de São Paulo.

\section{ALTERAÇÕES NOS ANOS 1970}

A década de 1970 trouxe grandes mudanças no panorama da pós-graduação em nosso país. Implementou- se a separação entre stricto sensu e lato sensu. Embora ela já existisse em termos de uma resolução do extinto CFE (Conselho Federal de Educação) desde 1965, não era praticada. A partir da aprovação do I PNPG (Plano Nacional de Pós-Graduação), essa separação se tornou efetiva. Os cursos de mestrado e doutorado se direcionariam para a formação de professores e pesquisadores, que seriam os profissionais da academia, responsáveis pela manutenção da instituição universitária. O lato sensu se ocuparia dos cursos profissionalizantes.

A efetiva separação foi gradual, como, conseqüentemente, o aumento da produção científica. Não pode ser excluída desse contexto a atuação da Capes (Coordenação do Aperfeiçoamento do Pessoal do Ensino Superior), que passou a atuar não apenas como agência de fomento, mas também como elaboradora de critérios e avaliadora do desempenho de docentes e programas de mestrado e doutorado. Gradualmente, a partir dessa década, a produção científica tendeu a crescer no país, simultaneamente com o número de programas stricto sensu. Os efeitos das mudanças na pós-graduação alteraram o perfil da RAE, que então passou a ser revista predominantemente acadêmica ou científica. Também marcou o início de um processo de extensão nacional, publicando artigos provenientes de autores que fossem vinculados a outras instituições e não mais somente à EAESP.

Ainda nessa época, o blind review foi consolidado e decidiu-se que a RAE seria uma revista científica, alinhada com as mudanças que ocorriam na pós-graduação. Estas eram indicativas de uma tendência mundial, ou seja, a separação entre periódicos científicos e profissionais. 
O fenômeno ocorria também nos Estados Unidos e na Europa. Todavia, no caso da RAE, essa mudança foi lenta, e ainda durante boa parte da década de 1980, e mesmo na de 1990 , a revista continuou abrigando material de cunho gerencial ou profissional, embora o fizesse em percentuais cada vez menores. Assim, a RAE ia se consolidando como periódico exclusivamente acadêmico. A publicação, durante alguns anos, de uma versão que pretendia atingir o público profissional - a RAE Light - foi uma tentativa de manter ainda uma única revista. Aos poucos foi se percebendo a dificuldade disso, até que se adotou, já no início do século XXI, a separação definitiva com a criação da RAE-executivo, hoje GV-executivo.

Houve também um lado sombrio na década de 1970, que foi o recrudescimento da repressão por parte do regime. Não se pode afirmar que a repressão tenha se estendido à universidade e à comunidade acadêmica em sua totalidade. Mas alguns setores e pessoas sentiram o peso do braço arbitrário do governo. Foi o caso das ciências sociais. Chegou-se a temer, não apenas no país, mas também no exterior, que as ciências sociais fossem banidas da universidade e do sistema educacional brasileiro. Felizmente isso não ocorreu. Mas não faltaram aposentadorias compulsórias, afastamentos, cassações de direitos e, em muitos casos, prisões e arbitrariedades lamentáveis, chegando, não raramente, à violência física contra profissionais da academia.

Durante boa parte do regime militar, tivemos também a censura primeiramente à mídia, mas que acabava colhendo também publicações acadêmicas. No clima de então, revistas de ciências sociais eram particularmente visadas. Isso fez com que a RAE acabasse por incluir em suas páginas muitos artigos de economia, sociologia, ciência política e outras ciências sociais que, pelo seu conteúdo, teriam problemas em aparecer nas revistas de suas áreas respectivas. A Administração era uma área que, pela porosidade de suas fronteiras, poderia abrigar contribuições de diversas outras disciplinas. E também se deve mencionar que uma revista de Administração chamava menos a atenção dos censores do que as de economia, sociologia e demais ciências sociais. Mas isso não serviu de salvo-conduto para que a RAE atravessasse incólume o tumultuado oceano da censura. Embora nunca tenhamos sido censurados com apreensão de números e com a presença de censores na Redação, recebemos advertências claras de que certos materiais não deveriam ser publicados. Lembro-me que alguns tópicos se tornaram quase ícones para criticar a política econômica do governo. Um deles era a questão da distribuição de renda. Era um tópico absolutamente intocável. A mídia impressa, falada ou televisiva não poderia mencionar o assunto. Já a RAE acabou por publicar vários artigos sobre a matéria, escrita por autores que eram críticos da política econômica governamental.

Quase 30 anos depois, essa situação deve ser vista como recusa em aceitar o contexto repressivo então existente no país. E também como reafirmação da crença na liberdade de expressão, indispensável à produção científica, e um desculpável desvio de curso na política editorial de uma revista de administração que publicou material, a rigor, fora de sua área.

\section{A RAE HOJE E 0 SEU FUTURO}

Atualmente, a RAE, juntamente com algumas poucas outras revistas, des- fruta da condição de ser classificada no sistema Qualis da Capes como "Nacional A". O que significa que ela ocupa a posição mais elevada a que uma revista nacional pode aspirar. Indaga-se se isso é suficiente para que se esteja satisfeito com a revista. Minha resposta retoma o tema da ambivalência que utilizamos ao iniciar este texto. Não há dúvida que é motivo de satisfação em nosso 45o aniversário, mas isso não nos deve impedir de apontar os sérios problemas que ainda temos e que deverão ser superados. Como no passado, os problemas e realizações da RAE mantêm com a comunidade científica uma relação de causalidade recíproca. Ela auxilia na promoção do aprimoramento da produção científica dessa comunidade, mas é também o reflexo das realizações e da melhoria da qualidade do que é produzido pela comunidade.

O aprimoramento da qualidade é talvez o principal problema. Se a revista é "Nacional A", deve publicar artigos compatíveis com a produção científica de programas de cúpula do sistema, ou seja, programas que mereçam da Capes avaliações de 6 a 7 . Segundo esses critérios, um programa 6 deve ter 25\% de seu corpo docente publicando em revistas internacionais de níveis "A" e "B". Se o programa merecer uma avaliação 7 , esse percentual se eleva para $40 \%$. Ora, se a RAE está a publicar o que de melhor há da produção científica do país, abre-se a questão de saber se o que é submetido à revista não poderia ser igualmente submetido, avaliado e publicado por revistas internacionais "A" e "B". A resposta dos mais otimistas sobre nossa produção seria pelo menos incerta. Acredito que a maioria concordaria que a RAE e as demais revistas que constam do Qualis como "A" possivelmente não seriam consideradas no mesmo nível 
internacionalmente. Isso nos leva a ter que rever o papel a ser desempenhado por uma revista "Nacional A".

A RAE deve atuar como uma fomentadora da qualidade da produção científica. Hoje os editores não se vêem mais confrontados com a falta do que publicar. Isso era comum no passado, quando as publicações científicas se iniciaram no país. O que temos hoje é felizmente um quadro inverso. Grande número de submissões, permitindo ao editor e aos avaliadores realizarem um processo de seleção realmente severo. $\mathrm{O}$ índice de seletividade da RAE não é muito diferente do das publicações "A" internacionais: publicase entre 7 e $10 \%$ do que é submetido.

Mas para que uma revista científica atue como fomentadora da qualidade do que é lhe submetido se faz necessário um grande envolvimento dos avaliadores. Esse atualmente é um ponto crítico. Os avaliadores são membros seniores da comunidade acadêmica individualmente sobrecarregados com tarefas docentes, de orientação, tendo também que cuidar de suas próprias produções científicas. O tempo dedicado à avaliação de artigos de seus pares é prova de generosidade e cidadania acadêmica. Mas nem sempre o número de avaliadores é suficiente para que possamos avaliar e posteriormente acompanhar o processo de aprimoramento dos artigos. Não é incomum levar entre um e dois anos para que um artigo tramite da submissão à publicação nas revistas internacionais de nível "A", podendo levar até três anos. Durante esse percurso, o que se estabelece é um diálogo franco, crítico e voltado à melhoria do material submetido entre avaliadores e autores, sempre com a intermediação do editor.
Outro desafio é o impacto. Difícil de ser medido, mas há já uma metodologia estabelecida e utilizada por periódicos internacionais. Alguns dados preliminares, resultantes de uma pesquisa recentemente realizada, indicam que o impacto da RAE não é o desejado. Isso pode ser atribuído ao fato de que a maioria dos membros da comunidade científica brasileira ainda toma periódicos internacionais como referência para sua atualização científica. O fato já foi detectado por autores brasileiros que realizaram análises de conteúdo de nossa produção científica e constataram que os autores estrangeiros são majoritariamente referidos e os nacionais, escassamente. Portanto, o reduzido impacto da RAE e, imagino, de outros periódicos brasileiros, seria explicado pela mesma tendência. Mas acredito que o aumento do impacto ocorrerá gradualmente. Hoje seria interessante que se verificasse, por exemplo, o impacto dos anais dos Enanpads. A quantidade de citações e de artigos que tomam como base os referidos anais me parece grande. O aumento do impacto do que é publicado sobre o restante da produção científica implica um processo de construção gradual. À medida que a comunidade amadurece e se sente mais segura de si, tende a se auto-referir com maior freqüência. Assim, o impacto de periódicos nacionais tende a aumentar.

A questão da internacionalização da RAE passa inevitavelmente pela questão da língua portuguesa. $O$ português não é uma língua internacional. Não é tampouco uma língua de cultura. Entende-se por língua de cultura um idioma que possa ser usado para que se tenha aces- so a um volume maior de publicações, independentemente do interesse específico pela cultura, literatura e história dos povos que falem a referida língua. Nesse sentido, o inglês pode ser visto como uma língua de cultura. O aprendizado do inglês raramente se faz por que se tenha interesse na literatura, história e cultura dos povos que o falam. Mas por que, ao conhecê-lo, acabamos por ter acesso a uma quantidade razoável de informações que, se não foram escritas originalmente em inglês, foram posteriormente vertidas a fim de permitir sua divulgação. Nada disso acontece com o português. É um idioma que internacionalmente tem menor alcance e penetração do que o espanhol.

$\mathrm{E}$, finalmente, a RAE enfrenta uma questão que, a médio e longo prazo, afeta os periódicos científicos, ou seja, a forma de circulação: impressa ou eletrônica. Há um acordo silencioso dentro da comunidade acadêmica de que o futuro será eletrônico. Vivemos um período de transição em que o conteúdo impresso é disponibilizado eletronicamente depois de algum tempo. Isso tem variado entre um e três anos para a maioria dos periódicos. O próximo passo pode ser a venda simultânea de assinaturas impressas e eletrônicas. Algumas revistas de notícias já adotam esse procedimento. Não me parece descabido para publicações científicas.

Mas, por ora, façamos o que se espera que nunca se deixe de fazer numa festa de aniversário. Cantar "Parabéns a você" para a nossa RAE, estendendo, porém, a homenagem e a celebração a toda a comunidade que a trouxe aonde ela hoje se encontra; e não esquecer que a instituição que a abriga é a EAESP da Fundação Getulio Vargas. 